\title{
Language Socialization and Identity in Learning*
}

\author{
Yan Lin \\ School of Humanities \\ Tianjin Polytechnic University \\ Tianjin, China
}

\begin{abstract}
This paper presents the research design and methodology, the approach to data collection and analysis and the pedagogical implications of a small scale study into the learning experience of full-time international students on MSc in TESOL. The focus is the socialization processes and identity formation and the pedagogical implication relate to the role of tutors, the use of VLE and the value of opportunities to reflect and interact as components of learning.
\end{abstract}

Keywords-language socialization; identity; learning experience

\section{INTRODUCTION}

Language socialization refers to secondary socializations throughout life to specialized forms and uses of language in school, community, and work settings. It includes cultural, pragmatic and other forms of learning apart from language learning. (Longman Dictionary of Language Teaching and Applied Linguistics, 2003:492) Ochs (1986) thinks language socialization is "the study of how novices of all ages 'acquire tacit knowledge and principles of social order and systems of belief through exposure and participation in language mediated activities"”.

Building an identity consists of negotiating the meanings of our experience in social communities. The concept of identity serves as a pivot between the social and individual, so that each can be talked about in terms of the other. It avoids a simplistic individual-social dichotomy without doing away with the distinction. The resulting perspective is neither individualistic nor absolutely institutional or societal. It does justice to the lived experience of identity while recognizing its social character - it is the social, the cultural, the historical with a human face. (Wenger, 1998:145)

This research studies the learning experience of international full-time students on MSc in TESOL in the applied linguistics by exploring their socialization and identity formation in an English-speaking country.

\section{RESEARCH DESIGN AND METHODOLOGY}

\section{A. Research Subjects}

8 Participants from 6 Different Countries (See the following "Table I")

\footnotetext{
* Study of Development of Foreign Language Proficiency Standard in Universities in China, Tianjin Philosophy and Social Science Program 2015 (Program No. TJWW15-018)
}

TABLE I. PARTICIPANTS' PROFILE

\begin{tabular}{|c|l|l|l|l|}
\hline No. & Name & Gender & Age & Nationality \\
\hline $\boldsymbol{1}$ & Salwa & Female & 23 & Brunai \\
\hline $\boldsymbol{2}$ & Katie & Female & 24 & China \\
\hline $\boldsymbol{3}$ & April & Female & 26 & Hongkong, China \\
\hline $\boldsymbol{4}$ & Jenny & Female & 26 & Korea \\
\hline $\mathbf{5}$ & George & Male & 31 & Spain \\
\hline $\boldsymbol{6}$ & Matt & Male & 32 & Poland \\
\hline $\boldsymbol{7}$ & William & Male & 24 & Thailand \\
\hline $\boldsymbol{8}$ & Wei & Male & 24 & China \\
\hline
\end{tabular}

\section{B. Research Instruments}

- Interview

- E-journals

- Narrative workshop

\section{Research Procedures}

The research lasts for 6 months. Firstly the participants were chosen from the same tutor-group and emails were sent asking for their agreement by replying a consent letter (presentation on the research objectives and the confidentiality). All of the eight candidates responded enthusiastically concerning their participation. Both individual interview and narrative workshop were conducted as for the life experience and learning experience of the candidates', and research-tasks were set: writing of Ejournals with guidelines given by the researcher by emails.

\section{DATA COLLECTION AND ANALYSIS}

\section{A. Interview}

The approach to individual interviews was based on Kvale's (1996) interview perspective: we sought to develop a co-construction of each student's learning experience. Interview questions such as: 1.How would you describe your learning experience before the start of the course? 2. What are your goals for the MSc TESOL? 3. Do you have difficulties in your life here? If any, what are they academically or culturally speaking?

All the eight participants demonstrated interest in the issues and cooperated and responded honestly in their answers. All of them have identities as successful, competent English language learners shown from their being admitted to that renowned university, all of them possess teaching 
experience (a prerequisite for the application for the pathway of TESOL), they also show an absence of strong learners identity. Some see the learning as a preparation for the next stage, i.e. an access to a $\mathrm{PhD}$ program (Salwa, Katie and Wei); some regard it as a back-up of teaching, i.e. to promote their teaching (Matt, George, William); some want to strengthen their academic learning competency by being involved in the professional environment (Katie and April); some intend to know people from different countries, academically and culturally. Concerning difficulties, the candidates' academic listening, reading and writing elements are very big challenges, they haven't got much training on discussion on academic topics, esp.in English; they still feel uneasy and embarrassed talking with native English speakers and feel they can not be acculturated socially.

\section{B. E-journals}

E-journals are devised to allow students a space to describe their learning experience by responding to emails addressed by the researcher periodically. Two E-journals with guidelines were designed: one was written at the very beginning of the research, i.e. two weeks after the program started. Some guided questions such as:

1. What are your gains during the last two weeks?

2. How do you feel your experience of study here will contribute to your learning?

3. If you are asked to refer to a book, what strategies would you use?

- Using the title of the book?

- By mentioning the author and the title of the book?

- Using the name of the author and the date of its publication?

4. What is your view of the role of the following in your learning?

- Individual learning/Collaborative learning

- Virtual Learning Environments such as "Blackboard" and "Discussion Board"

- Assignments

- Lectures and seminars

- Tutorials.

The second E-journal was asked to be written two months later, i.e. shortly before the completion of the taught modules of the semester to investigate the candidates' changes. Some guided questions such as:

1. How would you describe your experience in the past two months?

2. Can you trace some changes in your views and expectations? If any, in what ways?

Questions 3 and 4 are exactly the same with those Questions 3 and 4 in the first E-journal.
All participants replied, some briefly and some at greater length. All of them claimed the supportive roles played by Ejournals: they are aware of their changes in that helpful perspective; they are instructed the research methodology in an indirect and unconscious way; they sustain them through the difficult periods in learning, etc.

One striking point on Question 3 need to be noticed: all the 8 participants mentioned their changes in referring to a book by mentioning the author and the date of publication regardless of their answer in the first E-journal, which is a promising sign showing that they develop their academic learning ability by observation of the researcher's research procedures, by being devoted to their learning activities in the program and by identity formation.

\section{Narrative Workshop}

As a complement to data collection and analysis, by the end of the semester, a narrative workshop was carried out. The researcher led the workshop, which she audio-recorded by a voice-recorder and transcribed. The workshop was loosely structured and the participants were enthusiastically involved. The workshop was beneficial in examining students' problems and confusions in their learning experience, their learning achievements in the semester and in exploring the factors which influence these.

\section{RESEARCH FINDINGS AND PEDAGOGICAL IMPLICATIONS}

Tutors play important roles in the taught programs, particularly in mapping knowledge and modelling analysis and argumentation procedures.

In the electronic information age, the use of Virtual Learning Environments such as "Blackboard" and "Discussion Board" as learning tools should be promoted. "Blackboard" can be used as a database for all learning materials, the tutors upload the materials and the students can see the class materials in advance, they can download the materials and review lessons. "Discussion Board" is another learning tool for students' interaction concerning homework, assignments and other academic issues, while according to the narrative workshop, DB should be made a bi-dimensional platform on which tutors and students interact actively and supportively.

Collaborative learning both in and outside the class should be encouraged. Learning groups (or reading groups) can be promoted, but ensure students are responsible for organizing them and establishing specific topics for discussion. Although some students show hesitancy about the collaborative learning, in the narrative workshop there is overall positive evaluation, thinking it as useful and efficient.

Informal language development can be achieved by "visiting locals' houses", this can help the students know about the target language and the host culture. In turn, they develop their identity, and a strong sense of self can be formed and thus the confidence to engage in the struggle of learning to create the values of the unfolding life. 


\section{CONCLUSION}

Students in general can manage their learning effectively. There is much variation in their leaning processes and outcomes, partly due to their different learning identity and socialization involvement.

Language socialization is helpful for understanding participation and progress in programmes of learning. Language socialization combines well with identity and community of practice theory in explaining learning as successful accommodation to the society and other demands and challenges of a new environment.

\section{REFERENCES}

[1] Morita, N. (2004) "Negotiating Participation and Identity in Second Language Academic Communities". TESOL Quarterly (38)4:573-603.

[2] Norton, B. (2000) Identity and Language Learning: Gender, Ethnicity and Educational Change.London: Longman.

[3] Ochs, E.(1986) Introduction.In: Schieffelin \& E.Ochs (Eds). "Language socialization across cultures" (pp.1-16). Cambridge, UK: Cambridge University Press.

[4] Richards, J.C. \& Richard Schmidt (2003), Longman Dictionary of Language Teaching and Applied Linguistics (p.492), Beijing: Foreign Language Teaching and Research Press.

[5] Shi, X.(2006) "Intercultural Transformation and Second Language Socialization".Journal of Intercultural Communication. Issue 11:2-17.

[6] Wenger, E. (1998) Communities of practice: Learning, meaning, and identity. New York: Cambridge University Press. 